\title{
Phenotypic analysis of images of zebrafish treated with Alzheimer's $\gamma$-secretase inhibitors
}

\author{
Dilyara Arslanova', Ting Yang ${ }^{1}$, Xiaoyin Xu², Stephen T Wong ${ }^{3}$, Corinne E Augelli-Szafran ${ }^{1}$, Weiming Xia ${ }^{{ }^{*}}$
}

\begin{abstract}
Background: Several $\gamma$-secretase inhibitors (GSI) are in clinical trials for the treatment of Alzheimer's disease (AD). This enzyme mediates the proteolytic cleavage of amyloid precursor protein (APP) to generate amyloid $\beta$ protein, $A \beta$, the pathogenic protein in AD. The $\gamma$-secretase also cleaves Notch to generate Notch Intracellular domain (NICD), the signaling molecule that is implicated in tumorigenesis.

Results: We have developed a method to examine live zebrafish that were each treated with $\gamma$-secretase inhibitors (GSI), DAPT \{N- [N-(3,5-Difluorophenacetyl-L-alanyl)]-S-phenylglycine t-Butyl Ester\}, Gleevec, or fragments of Gleevec. These compounds were first tested in a cell-based assay and the effective concentrations of these compounds that blocked $A \beta$ generation were quantitated. The mortality of zebrafish, as a result of exposure to different doses of compound, was assessed, and any apoptotic processes were examined by TUNEL staining. We then used conventional and automatic microscopes to acquire images of zebrafish and applied algorithms to automate image composition and processing. Zebrafish were treated in 96- or 384-well plates, and the phenotypes were analyzed at 2, 3 and 5 days post fertilization (dpf). We identified that AD95, a fragment of Gleevec, effectively blocks $A \beta$ production and causes specific phenotypes that were different from those treated with DAPT. Finally, we validated the specificity of two Notch phenotypes (pigmentation and the curvature of tail/trunk) induced by DAPT in a dose-dependent manner. These phenotypes were examined in embryos treated with GSIs or AD95 at increasing concentrations. The expression levels of Notch target gene her6 were also measured by in situ hybridization and the co-relationship between the levels of Notch inhibition by DAPT and AD95 and the severity of phenotypes were determined.

Conclusion: The results reported here of the effects on zebrafish suggest that this newly developed method may be used to screen novel GSls and other leads for a variety of therapeutic indications.
\end{abstract}

\section{Background}

High throughput screening in invertebrate animals has emerged as a powerful tool for drug discovery, but whole vertebrate animal-based high throughput screening has yet to be developed and refined. The zebrafish is one of the most cost-effective vertebrates that can be used for high throughput and high content screens. Phenotype-based small molecule screening in zebrafish has been described in a number of studies [1]. One successful screen used a previously characterized mutant zebrafish, Gridlock, that is defective in aortic blood flow reminiscent of aortic coarctation in humans [2]. A

\footnotetext{
* Correspondence: wxia@rics.bwh.harvard.edu

${ }^{1}$ Center for Neurologic Diseases, Department of Neurology, Brigham and Women's Hospital, Harvard Medical School, Harvard University, Boston, MA,
} USA

(c) 2010 Arslanova et al; licensee BioMed Central Ltd. This is an Open Access article distributed under the terms of the Creative Commons Attribution License (http://creativecommons.org/licenses/by/2.0), which permits unrestricted use, distribution, and reproduction in any medium, provided the original work is properly cited. library of 5,000 small molecules was applied to Gridlock embryos, followed by manual examination using fluorescence microangiography. Two small molecules were identified to suppress the Gridlock phenotype in a dosedependent manner [3]. For non-fluorescent zebrafish, we have developed algorithms to analyze certain morphological changes in the development of zebrafish somites [4]. These changes in morphology were linked to the lack of a component of the $\gamma$-secretase [5], the key protease involved in the pathogenesis of Alzheimer's disease (AD) [6].

$\mathrm{AD}$ is a progressive neurodegenerative disorder that is pathologically characterized by the presence of extracellular and intracellular lesions known as amyloid plaques (extracellular) and neurofibrillary tangles (intracellular) [6]. Amyloid plaques are formed by the accumulation of

\section{Biomed Central}


amyloid $\beta(\mathrm{A} \beta)$, a $4 \mathrm{kDa}$ peptide that is generated by sequential cleavage of amyloid precursor protein (APP) by $\beta$-secretase and $\gamma$-secretase [6,7]. $\gamma$-Secretase is an aspartyl protease that mediates the final cleavage to generate $A \beta$ at residue $40(A \beta 40)$ or $42(A \beta 42)$. It is composed of presenilins (PS1 or PS2), presenilin enhancer (Pen-2), nicastrin, and Aph-1 [8-10]. PS carry the active site of the $\gamma$-secretase [11], and missense mutations in PS genes account for majority of early onset familial AD cases. $\gamma$-Secretase has also been identified as the key protease involved in the pathogenesis of certain types of cancers, such as leukemia [12].

Inhibiting the production of $\mathrm{A} \beta$ by targeting $\gamma$-secretase constituents is an attractive approach for developing new treatments of $\mathrm{AD}$, but has potential toxic side effects. Finding inhibitors of $\gamma$-secretase complex to simply block $A \beta$ production is no longer a challenge, and a number of potent $\gamma$-secretase inhibitors (GSIs) have been published [13]. However, inhibiting $\gamma$-secretase not only prevents APP cleavage and A $\beta$ production, but also blocks the cleavage of other important proteins. $\gamma$-Secretase cleaves dozens of other type I transmembrane proteins that are critically involved in many metabolic pathways, including Notch [14]. When both PS1 and its homolog PS2 are knocked out, the resulting phenotype is indistinguishable from the Notch knockout, and no $A \beta$ is produced [15]. In mice, Notch deficiency produces embryonic-lethal phenotypes, demonstrating the essential nature of Notch signaling in embryonic development.

Notch signaling plays an important role in health and disease states during embryonic development throughout adulthoods. $\gamma$-Secretase cleaves Notch encoded transmembrane receptor and activates signal transduction by releasing the Notch intracellular domain (NICD) [16]. NICD controls transcription of hairy and enhancer of split genes, such as hes1 in mammals [17] and her6 in zebrafish $[18,19]$. Hes genes are essential effectors of Notch signaling that regulate the maintenance of undifferentiated cells [20]. In rats lacking Hes1, Hes3, or Hes5, all neural stem cells prematurely differentiate into neurons without generating glial cells. This causes a wide range of brain defects in size, shape and cell organization [21]. In zebrafish, Notch is extremely important in embryonic development and is one of the driving forces behind neural crest cell differentiation. Inhibition of Notch signaling leads to extensive defects in organs derived from neural crest cells. The two most prominent phenotypes in zebrafish are somitogenesis and pigmentation. These phenotypes are illustrated in many zebrafish Notch pathway mutants, such as bea, des, aei, and wit $[22,23]$. Treating zebrafish with a potent $\gamma$-secretase inhibitor (GSI), DAPT, at the late blastula stage causes defects in somitogenesis and neurogenesis [24].
Similarities have been observed between DAPT-treated embryos and Notch pathway mutants, and certain phenotypes in DAPT treated embryos can be partially rescued by microinjection of NICD mRNA [24].

The implication of Notch signaling in cancers arose from the observation that more than $50 \%$ of human $\mathrm{T}$ cell acute lymphocytic leukemia (T-ALL) has activating mutations in Notch1 gene. This results in constitutively active Notch signaling [25]. Perturbed Notch signaling has been associated with different types of tumor cell lines. It has been found that $\gamma$-secretase inhibitors suppress these tumorigenesis pathways by reducing Notch signaling [26-28]. Interestingly, a recent study found that a combination of enhanced Notch signaling and Abelson leukemia (Abl) tyrosine kinase activity promotes acute lymphocytic leukemia [29]. Gleevec has been approved for the treatment of chronic myeloid leukemia and gastrointestinal stromal tumors, and mechanistically, Gleevec binds to Abl tyrosine kinase and locks the kinase in an inactive conformation by interacting with aspartate and phenylalanine [30-32]. In addition, Gleevec was shown to selectively inhibit APP cleavage and $A \beta$ production at high concentrations [33], in contrast to DAPT that blocks both APP and Notch cleavages. Therefore, the Gleevec molecule seems to contain functionalities that cause inhibition of Abl tyrosine kinase and $\gamma$-secretase independently. The co-crystal structure of the Abl tyrosine kinase domain and Gleevec shows that the pyrimidine and pyridine rings of the Gleevec overlap with the ATP-binding site via Thr315 [30-32]. The goal of this study is to dissect the structure of Gleevec and examine the effects of each fragment both in vitro and in vivo on $\gamma$-secretase cleavage of APP and Notch in cultured cell- and whole animal-based assays. To facilitate data collection, we developed a semi-automated method for embryo imaging and phenotype recording. This approach can be used for future development of high throughput screening of novel GSIs and other therapeutic leads for the treatment of $\mathrm{AD}$, leukemia, and other diseases.

\section{Methods}

\section{A. Embryo Treatment}

Embryos were placed in a 24-well plate (5-6 embryos/ well). Compounds were dissolved in $1 \mathrm{~mL}$ of egg water (final concentration at $50 \mu \mathrm{M}$ for DAPT $\{\mathrm{N}-[\mathrm{N}-(3,5-$ Difluorophenacetyl-L-alanyl)]-S-phenylglycine $t$-Butyl Ester\}, Gleevec, AD28, AD94, AD95, and $10 \mu \mathrm{M}$ for AD115; 0.1\% DMSO was used as a negative control). Embryo medium was replaced with the compound containing egg water, and the embryos were incubated at $28^{\circ} \mathrm{C}$ overnight before survival rate was recorded and photographic images were taken. Compounds were applied at two time points, 6 hours and 24 hours 
post-fertilization (hpf). Prior to the treatment at $24 \mathrm{hpf}$, embryos were de-chorionated in pronase [34]. Embryos treated at $6 \mathrm{hpf}$ were de-chorionated the following day after the compound treatment.

\section{B. Blocking $A \boldsymbol{\beta}$ production by $\boldsymbol{\gamma}$-secretase inhibitors} Compounds were dissolved in the DMEM growth media and applied to $\sim 90 \%$ confluent APP-expressing $\mathrm{CHO}$ cells in 96-well plates. After incubation for 4-5 hours at $37^{\circ} \mathrm{C}$, cells were centrifuged for 5 minutes at $6000 \mathrm{~g}$, and supernatant media were collected for $A \beta$ measurement by ELISA. Sandwich ELISAs for monomeric A $\beta$ were performed as described [35,36]. The capture antibodies $2 \mathrm{G} 3$ (to $A \beta$ residues $33-40$ ) and $21 \mathrm{~F} 12$ (to $A \beta$ residues 33-42) were used for $A \beta 40$ and $A \beta 42$ species. The detecting antibody was biotinylated 266 (to $A \beta$ residues 13-28). These antibodies were kindly provided by Dr. P. Seubert and Dr. D. Schenk (Elan, plc).

\section{TUNEL Staining}

To examine the apoptotic effect of the compounds on embryos, TUNEL staining was performed (In Situ Cell Death Detection Kit, TMR red, Roche). Embryos fixed in $4 \%$ paraformaldehyde overnight at $4{ }^{\circ} \mathrm{C}$, de-chorionated, and treated with $1 \%$ Triton-X100 in PBS. The reaction was carried out at $37^{\circ} \mathrm{C}$ for 1 hour, and all staining procedures were performed per the instruction by the manufacturer [5]. The embryos were mounted in $3 \%$ methylcellulose and images were acquired under $51 \times$ magnification.

\section{In situ Hybridization}

In situ hybridization was carried out according to standard protocols [37] using the her6 probe. Singlestranded RNA probes against her6 were synthesized from a cDNA clone (kindly provided by Dr. P Raymond, University of Michigan, Ann Arbor, MI) using T7 RNA polymerase after linearization by restriction digest, then labeled with digoxigenin-UTP (Roche, Basel, Switzerland). At least 10 to 20 embryos were examined in each experiment.

To quantify the expression levels of Notch downstream gene her6, we used manual approach to segment the her6-positive brain regions from the dorsal view images. The region of interest was manually segmented, and the intensity of each ROI was quantified. The levels of her6 expression in DMSO treated embryos were normalized to 1 , and relative levels of other embryos were calculated.

\section{E. Conventional Microscope Imaging}

Compound-treated embryos were observed under an OLYMPUS SZX12 microscope. For examination, embryos were removed from the compound-containing medium and placed in $0.4 \%$ tricane (3-amino benzoic acid ethyl ester, Sigma, St. Louis, MO) solution. Upon anesthetizing, embryos were placed in 3\% methylcellulose for positioning and images were recorded with an OLYMPUS Q-COLOR3 camera. Images were taken at $51 \times$ magnification for embryos at $2 \mathrm{dpf}$, and $40 \times$ magnification for embryos at 4 and $6 \mathrm{dpf}$.

\section{F. Automatic Imaging by In Cell Analyzer 1000}

Embryos were treated with compounds at two time points (6 hpf and $24 \mathrm{hpf}$ ) in the 96- or 384-well plates (1 embryo/well) with compound-containing media (final concentration at $50 \mu \mathrm{M}$ for all compounds except for 10 $\mu \mathrm{M}$ of $\mathrm{AD} 115)$. For image acquisition, tricane was added to the final concentration of $0.4 \%$ in the same plate, and the plate was loaded into In Cell Analyzer 1000 (General Electric Co., Fairfield, CT). Images of individual wells were automatically acquired by In Cell Analyzer 1000. From each well of the plate, $4 \mathrm{z}$-series were scanned from top to bottom, and 4-6 fields of each well were taken. Complete coverage of individual wells of the microtiter plate usually resulted in poor resolution and prevented further image processing. On average, 10 minutes were needed for the acquisition of images from a 384-well plate, and there was no effect on the development of zebrafish during this process. Images acquired by In Cell Analyzer 1000 were processed using MATLAB (Mathworks, Natick, MA), and fields from each well were automatically merged using "Merge" function from Adobe Photoshop Elements (Adobe Systems Inc., San Jose, CA). Using these approaches, the average time used for automatic image acquisition and processing was significantly reduced compared to conventional microscope-based image acquisition, which would require approximately 10-20 fold more time to analyze the same number of animals. Pigmentation was quantified in a semi-automatic approach. First, manual drawing of region of interest (ROI) on an image was carried out, followed by calculation of the optimum threshold separating the ROI into two classes, pigmentation and background [38]. The advantage of this method is that it minimizes the combined intra-class variances with a moderate computational complexity. However, the method may generate false-positive and false-negative due to uneven illumination and noise in the measurement. To circumvent this problem, a size-filter was used to discard small segmented areas when the areas are less than a small positive threshold $\alpha$ based on the prior knowledge that true pigmentation is usually larger than $\alpha$ pixels. In this work we set $\alpha$ to 10 . After segmenting the pigmentation, the total area and average pixel values of pigmentation were computed. The values of the normal control group were used as the benchmark for comparison. If the average pixel density of an 
image was less than the control group, it was marked as 'lighter'.

\section{G. In Vitro $\gamma$-Secretase Cleavage of Notch Substrate}

The E. coli generated Notch-based, 100-residue $\gamma$-secretase substrates N100-Flag were purified as previously described [39]. N100-Flag substrate contains an initiating methionine, 99 amino acids that start at the TACE cleavage site, and a Flag tag. Compounds were mixed with solubilized $\gamma$-secretase complex and the in vitro $\gamma$ secretase cleavage of Notch substrate was carried out as previously described [40].

\section{Results}

A. Reduction of $A \beta$ generation by fragments of Gleevec Three types of compounds were used to treat zebrafish embryos: DAPT (a well-established, potent GSI), Gleevec (a reported APP-selective GSI), and the fragments of Gleevec. Four individual Gleevec fragments were synthesized and designated as AD28, AD94, AD95, and AD115 (Fig. 1A). An APP overexpressing $\mathrm{CHO}$ cell line $7 \mathrm{~W}$ was treated with individual compounds and the levels of secreted $A \beta$ in the media were measured by ELISA. Levels of $A \beta$ in the media of $7 \mathrm{~W}$ cells that were treated with DMSO were normalized to 1 , and relative levels of $A \beta 40$ (Fig. 1B) and $A \beta 42$ (Fig. 1C) were calculated. As expected, cells treated with the potent GSI, DAPT, showed a strong inhibition of the generation of $\mathrm{A} \beta$, even at the concentration of $0.5 \mu \mathrm{M}$. At high concentration of $50 \mu \mathrm{M}$, both Gleevec and AD95 showed inhibition of $\mathrm{A} \beta$ production, while $\mathrm{AD} 28$ and AD94 showed less inhibition. AD115 failed to inhibit $A \beta$ production even at $100 \mu \mathrm{M}$ (Fig. 1B, C).

\section{B. Toxicity of GSI in zebrafish embryos}

We routinely generated large clusters of zebrafish embryos and treated several dozen embryos with each compound. To assess the effects of these compounds on<smiles>Cc1ccc(C(=O)Nc2ccc(C)c(Nc3ncccn3)c2)cc1</smiles>

B.

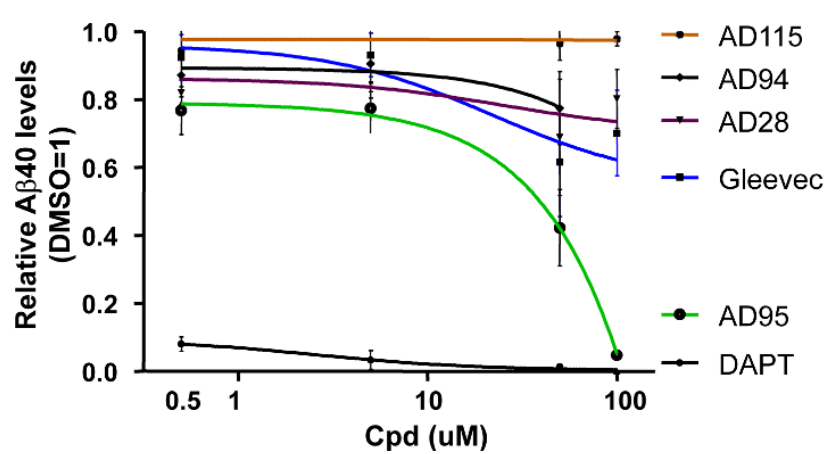

C.

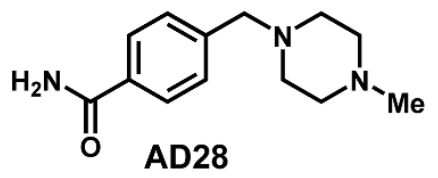

Figure 1 Inhibition of $\mathbf{A} \boldsymbol{\beta}$ production in cultured cells by fragments of Gleevec. A. Structures of Gleevec and its fragments used for the treatment of cultured cells and zebrafish embryos. Four fragments of Gleevec are named as AD28, AD94, AD95 and AD115. B and C. Inhibition of $\gamma$-secretase cleavage of APP was determined by measuring the levels of $A \beta 40$ (B) and A 42 (C) in the conditioned-media by ELISA. Levels of A $\beta$ from cells treated with $0.1 \%$ of DMSO were normalized to 1 and used to calculate the relative levels of A $\beta$ from cells treated with DAPT, Gleevec, and its fragments. Standard errors of means are illustrated by bars. 
Table 1 Survival rate of the compound treated embryos.

\begin{tabular}{cccc}
\hline Cpd & Conc. & Alive/Total Embryos & Alive/Total Embryos \\
\hline & & Day 1 & Day $\mathbf{2}$ \\
\hline DMSO & $0.10 \%$ & $35 / 37$ & $34 / 35$ \\
\hline DAPT & $50 \mu \mathrm{M}$ & $32 / 33$ & $30 / 32$ \\
\hline Gleevec & $50 \mu \mathrm{M}$ & $48 / 50$ & $47 / 48$ \\
\hline AD28 & $50 \mu \mathrm{M}$ & $28 / 28$ & $27 / 28$ \\
\hline AD94 & $50 \mu \mathrm{M}$ & $15 / 18$ & $15 / 15$ \\
\hline AD95 & $50 \mu \mathrm{M}$ & $17 / 18$ & $17 / 17$ \\
\hline AD115 & $50 \mu \mathrm{M}$ & $0 / 10$ & $0 / 0$ \\
\hline AD115 & $10 \mu ; \mathrm{M}$ & $33 / 34$ & $30 / 33$ \\
\hline
\end{tabular}

the zebrafish survival rate, we used a conventional microscope and quantified embryo survival rate at 1 and $2 \mathrm{dpf}$ (Table 1). When the concentrations of these compounds were at $50 \mu \mathrm{M}$, the survival rate of embryos treated with each of the compounds was close to $100 \%$ except for AD115. None of the embryos treated with 50 $\mu \mathrm{M}$ AD115 survived. When the concentration of AD115 was reduced to $10 \mu \mathrm{M}$, all embryos survived at $1 \mathrm{dpf}$, and about $90 \%$ survived at $2 \mathrm{dpf}$.

To determine whether these compounds induced regional apoptosis in zebrafish embryos, apoptotic cell death was assessed via TUNEL staining (Fig. 2).
Embryos were treated with $50 \mu \mathrm{M}$ of compounds (except AD115 was at $10 \mu \mathrm{M}$ ), and TUNEL staining of these embryos were compared to that of $0.1 \%$ DMSOtreated embryos. While DMSO treated embryos showed a few apoptotic cells throughout their bodies (Fig. 2A), compound-treated embryos showed some apoptotic cells mostly in the tail region. AD28 (Fig. 2D), AD95 (Fig. 2F), and AD115 (Fig. 2G) showed a comparable number of apoptotic cells to Gleevec-treated embryos (Fig. 2C). AD94 showed a slightly higher number of apoptotic cells in the tail compared to the other embryos (Fig. 2E), and DAPT did not induce extensive apoptosis in embryos compared to DMSO-treated embryos (Fig. 2B).

\section{Compound Induced Phenotypes in Zebrafish Embryos}

The zebrafish embryos treated with different compounds were examined every 1-2 days up to $6 \mathrm{dpf}$. Images were acquired by two methods using conventional microscope and microscopic instrument In Cell Analyzer. Morphological phenotypes of zebrafish embryos treated with DAPT, Gleevec or fragments of Gleevec by conventional microscope were compared first to document these phenotypes (Fig. 3). Images of compound-treated embryos were acquired at $2 \mathrm{dpf}$ (Fig. 3A), $4 \mathrm{dpf}$ (Fig. 3B) and 6 dpf (Fig. 3C). The DMSO-treated embryos showed a

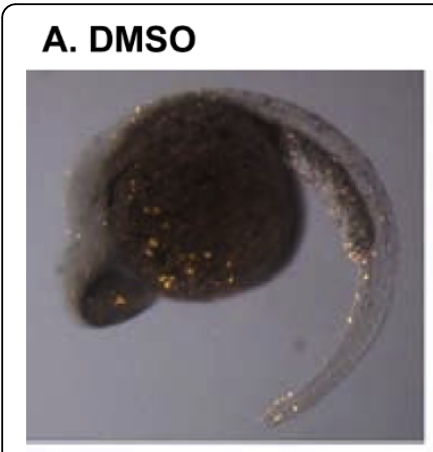

\section{B. DAPT}

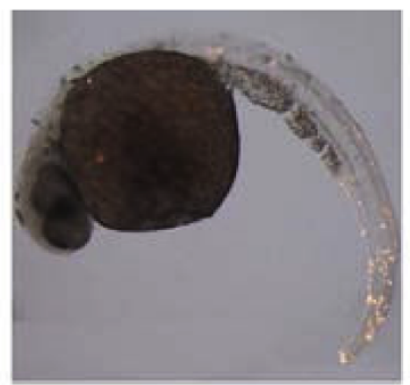

F. AD95

E. AD94
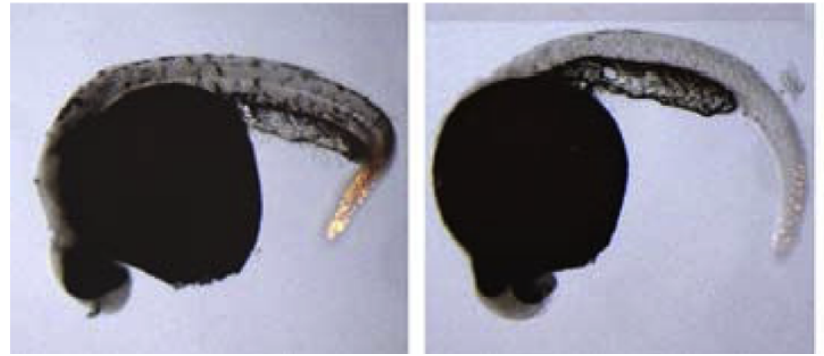

C. Gleevec

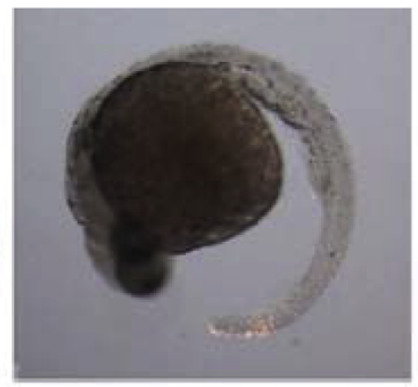

G. AD115

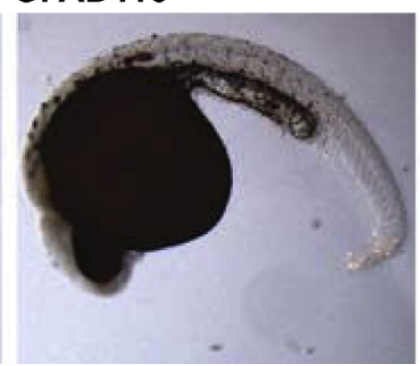

\section{AD28}

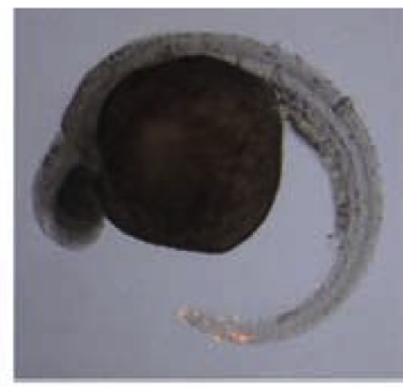

Figure 2 Apoptosis in zebrafish embryos treated with compounds. Zebrafish embryos were treated with GSI or fragments of Gleevec at 6 hpf. Embryos were then fixed and subjected to TUNEL staining at $24 \mathrm{hpf}$. Control embryos were treated with $0.1 \%$ DMSO and the remaining embryos were treated with different GSIs or Gleevec fragments at $50 \mu \mathrm{M}$, except for AD115 whose concentration was $10 \mu \mathrm{M}$. The majority of apoptotic cells were observed in the fish tail, but no difference among individual compound-treated embryos was observed. The representative images from 2 different experiments are presented. 
A.

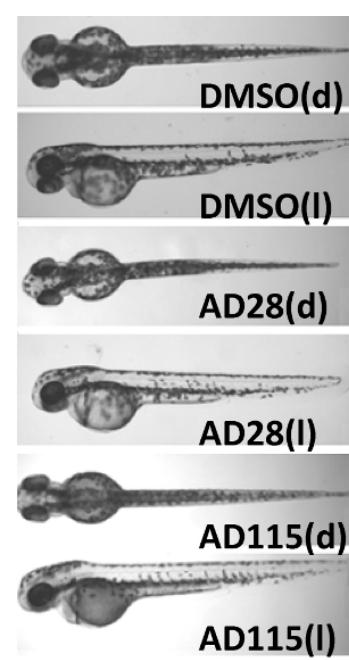

B.
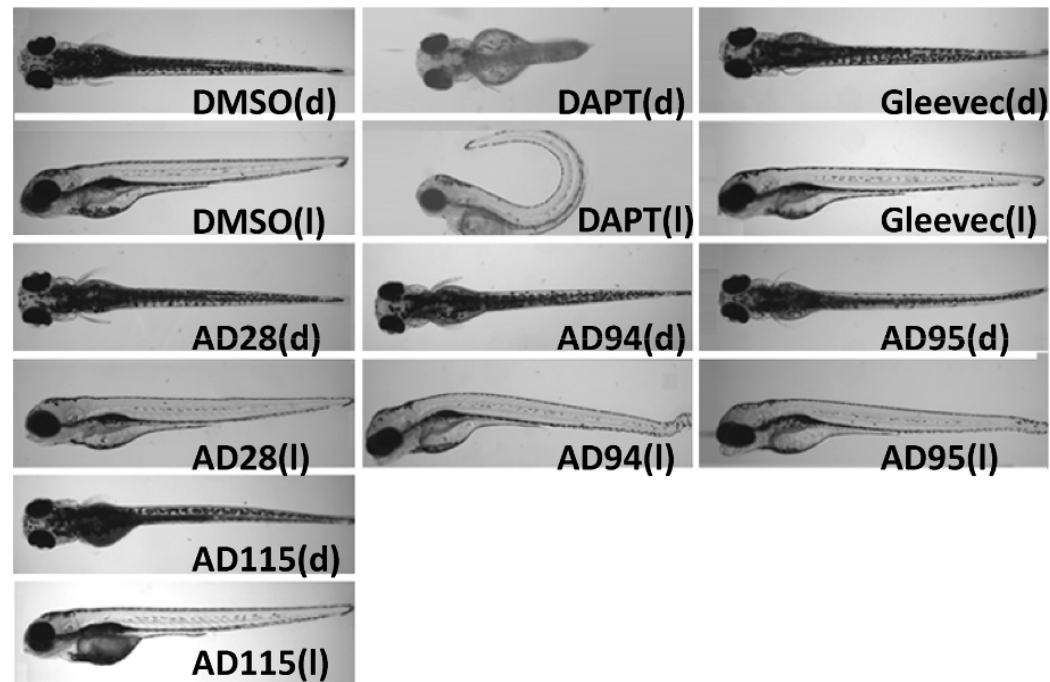

C.
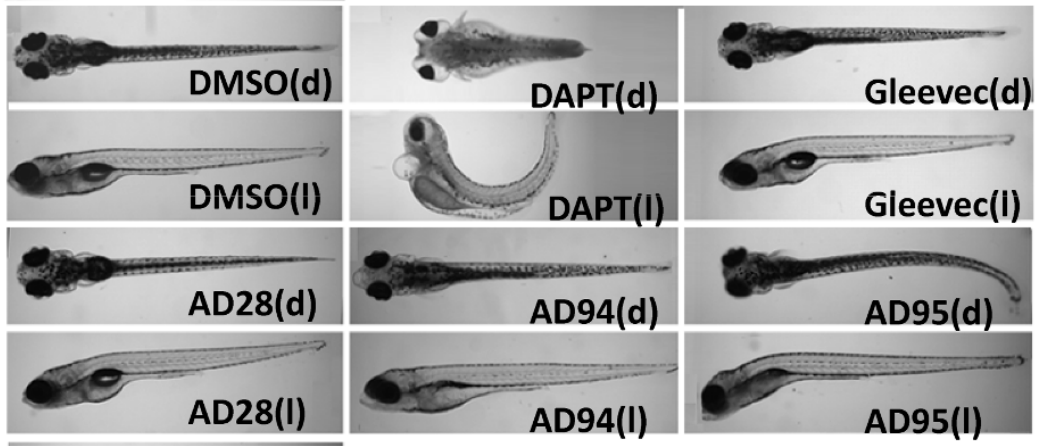

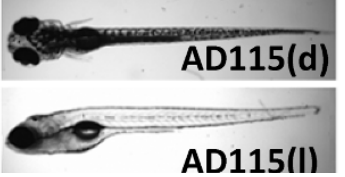

Figure 3 Phenotypes of the embryos treated with GSI, Gleevec, and fragments at $\mathbf{2 4}$ hpf. Dorsal view (indicated as " $\mathrm{d}$ ", top panel) and lateral view (indicated as "I", bottom panel) of embryos are shown. Control embryos treated with $0.1 \%$ DMSO show a wild-type phenotype. Embryos treated with GSI, DAPT, resulted in defects in somitogenesis, eye development, pigmentation, and trunk formation as observed at 2 dpf (A), $4 \mathrm{dpf}(\mathrm{B})$, and $6 \mathrm{dpf}(\mathrm{C})$. Embryos treated with DAPT, AD94 or AD95 started to show defects at $2 \mathrm{dpf}$, and phenotypes of remaining embryos were most obvious at 4 or $6 \mathrm{dpf}$. The following concentrations were used: $50 \mu \mathrm{M}$ DAPT, $50 \mu \mathrm{M}$ Gleevec, $50 \mu \mathrm{M}$ AD28, $50 \mu \mathrm{M}$ AD94, $50 \mu \mathrm{M}$ $\mathrm{AD} 95$, and $10 \mu \mathrm{M}$ AD115. 
wild-type phenotype and developed normally. Embryos developed normal eyes, straight trunk and tail (Fig. 3A), $\mathrm{V}$-shaped somites (Fig. 3B and $3 \mathrm{C}$ ), and normal pigmentation (6 dpf) (Fig. 3C). Embryos treated with DAPT, the potent GSI known to inhibit both APP and Notch processing, showed curved tail, a bent trunk (Fig. 3A, B), smaller eyes, disturbed somites, and a decrease in pigmentation (Fig. 3C). Almost all Gleevec-treated embryos developed normally with a phenotype similar to the wild-type embryos. Only 1 out of 40 Gleevectreated fish showed smaller size, and 4 out of 40 showed a shorter tail. AD28-treated embryos showed normal pigmentation and $\mathrm{V}$-shaped somites with the phenotypes similar to wild-type embryos. Less than $20 \%$ (5 out of 28) embryos showed short, slightly curved tails (Table 2).

Both AD94- and AD95-treated embryos showed defective phenotypes (Fig 3). While defective phenotypes were most obvious at the later stages, they were not lethal, and embryos were alive even at day 7. For AD94, embryos showed a smaller body size, smaller puffy eyes, a minor dorsally curved tail, and less pigmentation. For AD95, all fish displayed a bent trunk (1 embryo had a severely bent trunk), slightly curved tails, smaller body size, normal eyes, craniofacial defects, and a lighter pigmentation. For AD95-treated embryos, 1 out of 9 assessed zebrafish bodies showed signs of edema. However, AD95-treated embryos showed normal V-shaped somites similar to wild-type embryos, which was in contrast to DAPT-treated embryos that completely lacked $\mathrm{V}$-shaped somites (Fig. 3B).

Embryos treated with $10 \mu \mathrm{M}$ AD115 showed a slightly abnormal phenotype and variable defects. Overall, 8 out of 30 fish had edema at $2 \mathrm{dpf}$, and one embryo displayed a bent trunk (data not shown). Among 17 embryos examined at $4 \mathrm{dpf}$ and $6 \mathrm{dpf}, 2$ embryos had severe craniofacial abnormalities and did not survive beyond $6 \mathrm{dpf}, 5$ embryos showed tumors in the gut area, and 9 embryos showed craniofacial defects. Normal $\mathrm{V}$-shaped somites were found among all treated embryos, and most embryos showed slightly decreased pigmentation throughout the body and especially around the swim bladder. The detailed characterization and comparison of these phenotypes are listed (Table 2) and used as reference for subsequent analysis of images automatically acquired by In Cell Analyzer.

\section{Automatic image acquisition of compound treated embryos by In Cell analyzer}

In addition to conventional microscope imaging, compound-treated embryos at $6 \mathrm{hpf}$ were imaged by In Cell Analyzer (Fig. 4). This instrument is commonly used to perform high-throughput image acquisition of cultured cells living in 96- or 384-well plates. We adjusted the instrument for image acquisition of live zebrafish in microtiter plates. Upon high speed image acquisition by the instrument, several fields of images from the individual wells were automatically merged using "Merge" command from the Adobe Photoshop Elements. Most composed images contain the entire zebrafish body, but some images have truncations due to the nature of automatic image acquisition (Fig. 4). Because In Cell Analyzer did not capture the entire population of embryos in all wells, the number of analyzed zebrafish images was lower than the number of fish treated with compounds.

In addition, we de-chorionated embryos at $24 \mathrm{hpf}$, transferred them to 96 - or 384-well plates and treated individual embryos with different compounds. Images of the fish at 2, 3 and $5 \mathrm{dpf}$ were acquired by In Cell Analyzer and the phenotypes recorded (Fig. 5). No striking difference in phenotypes between embryos treated at 6 hpf (Fig. 4, Table 3) and 24 hpf (Fig. 5, Table 4) was observed. Images of DAPT or Gleevec-treated embryos automatically acquired by In Cell Analyzer at $2 \mathrm{dpf}$ and $3 \mathrm{dpf}$ were similar to those recorded by conventional microscope. At $5 \mathrm{dpf}$ or $6 \mathrm{dpf}$, lateral images were difficult to acquire since most fish maintained a dorsal orientation due to the development of the swim bladder.

The effects of compounds on pigmentation and embryo morphology, especially the tail and trunk, were readily observed. DAPT-treated embryos showed defects in tail curvature, pigmentation, eyes, and somite differentiation. Gleevec-treated embryos showed

Table 2 The phenotypes of compound-treated zebrafish imaged by conventional microscope.

\begin{tabular}{|c|c|c|c|c|c|c|}
\hline Cpd & Conc. & Size & Eye & Pigment & Tail & Trunk \\
\hline DMSO & $0.10 \%$ & normal & normal & normal & all straight & straight \\
\hline DAPT & $50 \mu \mathrm{M}$ & smaller & smaller & decreased & all curved & curved \\
\hline Gleevec & $50 \mu \mathrm{M}$ & normal & normal & normal & 4/40 short & straight \\
\hline AD28 & $50 \mu \mathrm{M}$ & normal & normal & normal & 5/28 slightly curved & straight \\
\hline AD94 & $50 \mu \mathrm{M}$ & Smaller & smaller swollen & Decreased & all slightly curved & curved \\
\hline AD95 & $50 \mu \mathrm{M}$ & smaller & normal & Decreased & all slightly curved & bent \\
\hline AD115 & $10 \mu \mathrm{M}$ & normal & normal & decreased around swim bladder & $11 / 30$ curved & straight \\
\hline
\end{tabular}




\section{A. 2dpf}
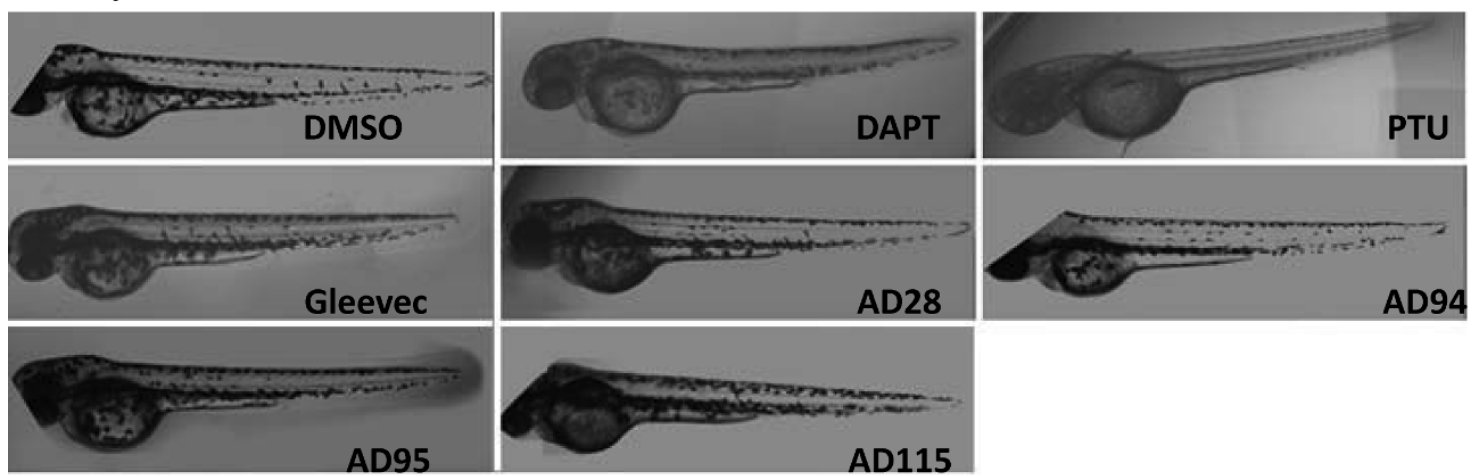

\section{B. 3dpf}
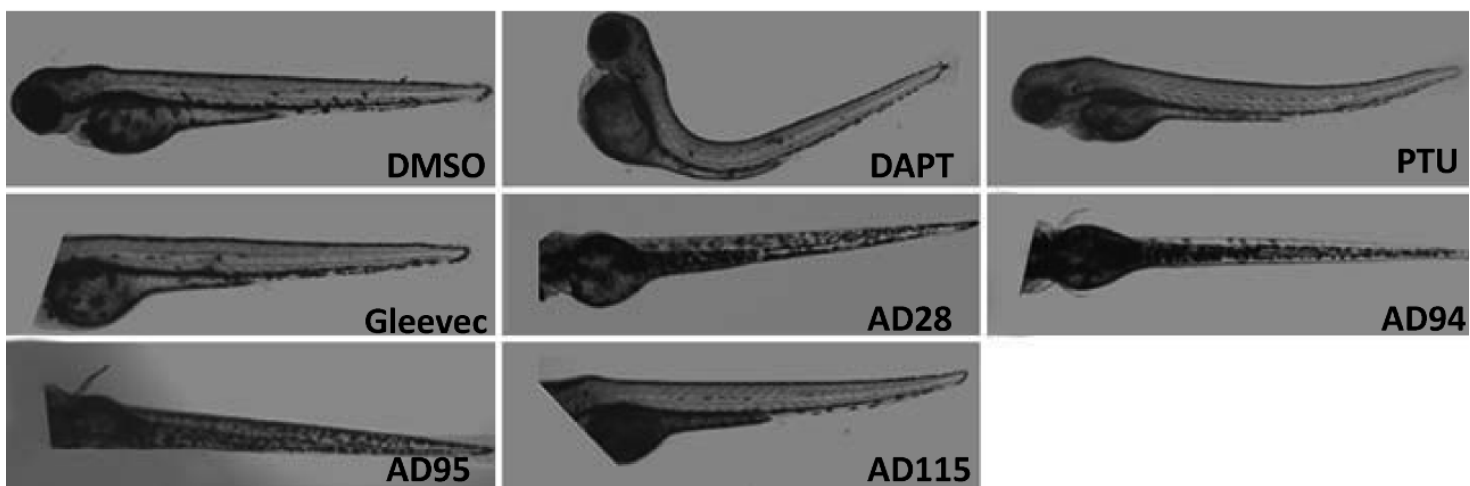

\section{C. $5 \mathrm{dpf}$}
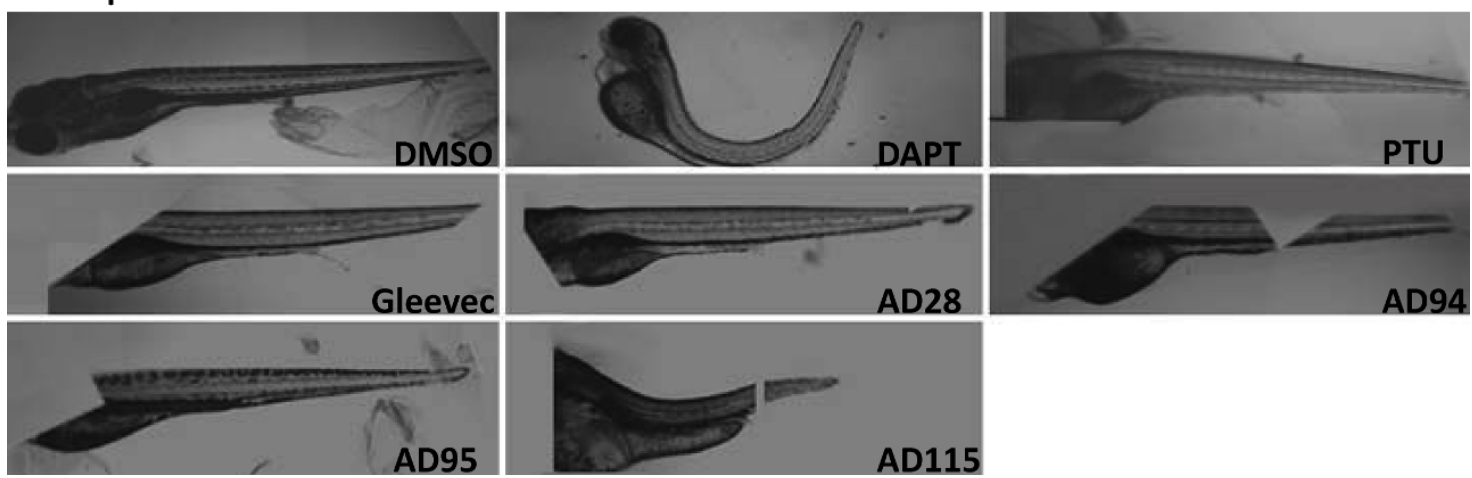

Figure 4 Automatically acquired images of embryos treated with GSI or fragments of Gleevec during early development stage (6 hpf) Embryos were treated with GSIs or Gleevec fragments at the following concentrations at 6 hpf: $0.1 \% D M S O, 50 \mu M$ for all compounds, except for $10 \mu \mathrm{M}$ AD115. Images of living zebrafish in microtiter plates were acquired by In Cell Analyzer at $2 \mathrm{dpf}(\mathrm{A}), 3 \mathrm{dpf}(\mathrm{B})$ and $5 \mathrm{dpf}(\mathrm{C})$, and several fields of images from the individual wells were automatically merged. Because the instrument acquired several fields that covered a portion of the microtiter plate well, some images show truncations of the zebrafish.

no phenotypic abnormalities. Of the Gleevec fragments, AD28-treated embryos showed no effect at 50 $\mu \mathrm{M}$. AD94 caused a slight reduction in pigmentation, and $\mathrm{AD} 115$ at $10 \mu \mathrm{M}$ decreased pigmentation around the swim bladder and caused curvature in the tails of several zebrafish. AD95 showed strong inhibition of $A \beta$ production and caused some phenotypes in zebrafish. Phenyl thiourea (PTU) is widely used to prevent pigmentation during embryonic development for observing transparent zebrafish anatomy. As expected, all of embryos that were treated with PTU showed decreased pigmentation (Table 3 and 4).

Zebrafish treated with $50 \mu \mathrm{M}$ of AD95 did not yield alteration in pigmentation. However, it caused curvature of tails with bent trunks. In embryos treated with $50 \mu \mathrm{M}$ of AD95 at $24 \mathrm{hpf}$, a small number of embryos showed 


\section{A. $2 \mathrm{dpf}$}
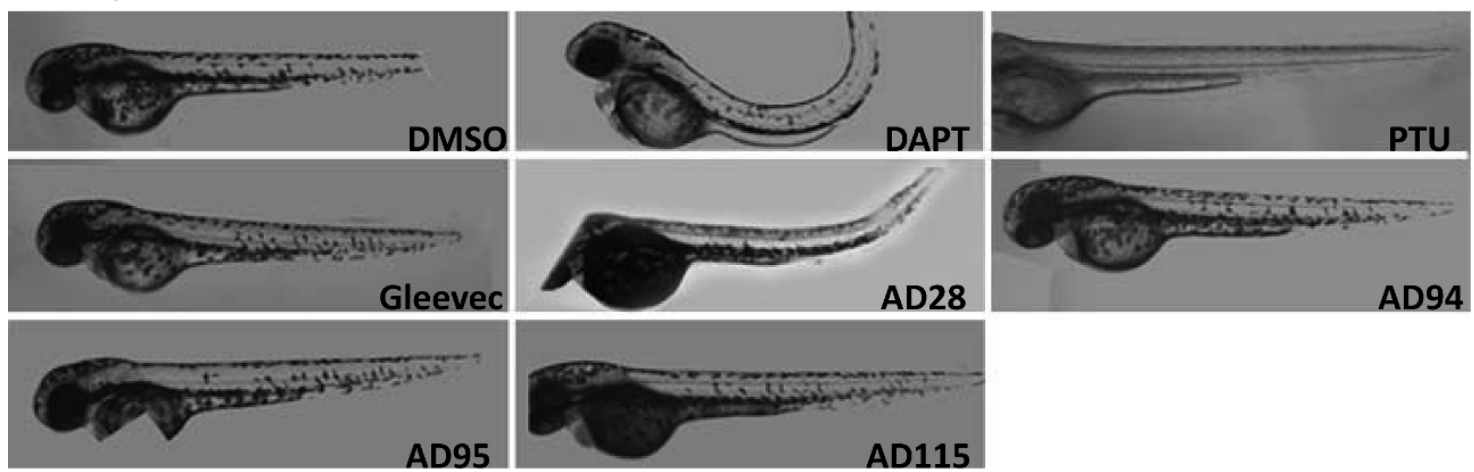

\section{B. 3dpf}
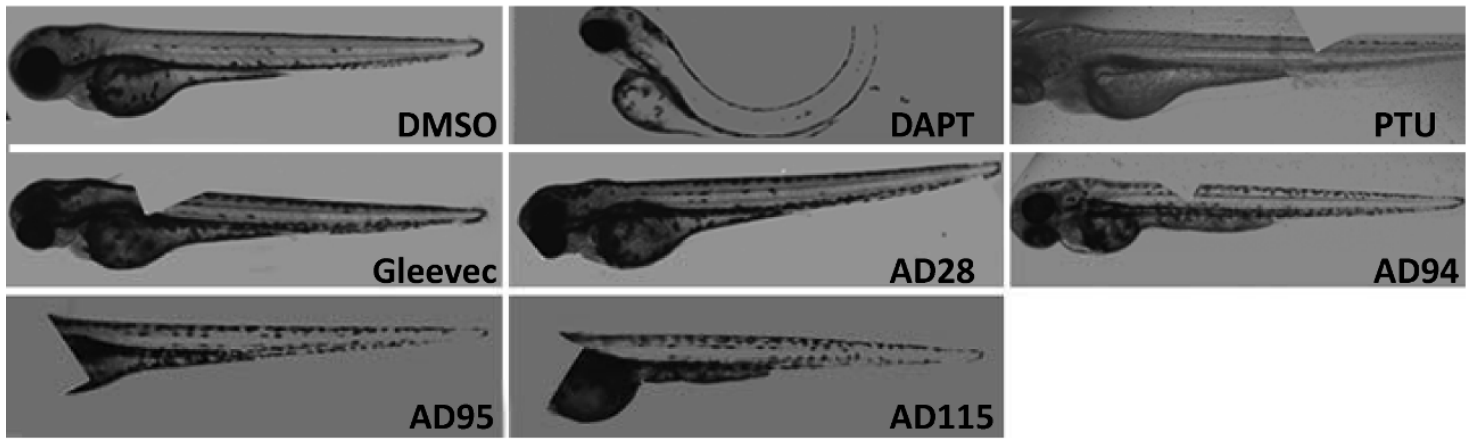

\section{C. $5 \mathrm{dpf}$}
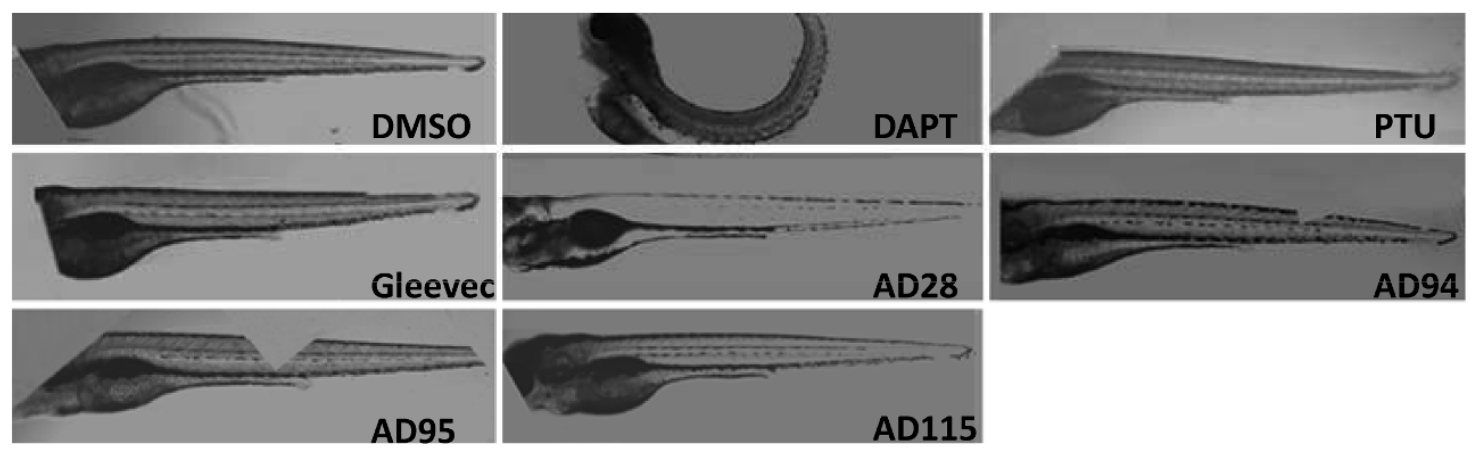

Figure 5 Automatically acquired images of embryos treated with GSI or fragments of Gleevec at $\mathbf{2 4}$ hpf. Embryos were treated with GSIs and fragments of Gleevec at $24 \mathrm{hpf}$, and $50 \mu \mathrm{M}$ of all compounds, except for $10 \mu \mathrm{M}$ of AD115, were applied to these embryos. Images of living zebrafish in microtiter plates were acquired by In Cell Analyzer at $2 \mathrm{dpf}(\mathrm{A}), 3 \mathrm{dpf}(\mathrm{B})$ and $5 \mathrm{dpf}(\mathrm{C})$, and the same procedures were followed to automatically merge several fields of images to compose the entire zebrafish.

edema. This was not observed in embryos treated with 50 $\mu \mathrm{M}$ of DAPT. Apparently, embryos treated with AD95 and DAPT at concentrations that effectively reduced $\mathrm{A} \beta$ production (Fig. 1B, C) show quite different phenotypes, such as the pigmentation (Table 3 and 4 ) and V-shaped somites (Table 2), as described earlier.

\section{E. Dose-dependent phenotypic changes in zebrafish} treated with increasing concentration of compounds To search for a possible dose-dependent effect, a greater number of embryos were treated with each compound with two or three different concentrations (Table 5). Embryos at 24 hpf (Fig. 6) were treated with these compounds and In Cell Analyzer was used to capture images of embryos at $2 \mathrm{dpf}$ (Fig. 6A), $3 \mathrm{dpf}$ (Fig. 6B) and $5 \mathrm{dpf}$ (Fig. 6C). DMSO- and untreated-embryos were used as a control. At $50 \mu \mathrm{M}$, DAPT-treated embryos showed tail curvature and decreased pigmentation. A minor reduction in pigmentation was also observed in embryos treated with $5 \mu \mathrm{M}$ DAPT, but no defects in tail curvature or trunk formation were detected at the lower concentration. The dose-response 
Table 3 Phenotypic description of the embryos treated at 6 hpf followed by automatic image acquisition.

\begin{tabular}{|c|c|c|c|c|c|}
\hline Cpd & Embryo Number & Conc. & Pigment & Tail & Trunk \\
\hline DMSO & 15 & $0.1 \%$ & normal & all straight & all straight \\
\hline DAPT & 18 & $50 \mu \mathrm{M}$ & decreased & $5 / 18$ curved & 10/18 curved \\
\hline Gleevec & 17 & $50 \mu \mathrm{M}$ & normal & all straight & $1 / 17$ short \\
\hline AD28 & 17 & $100 \mu \mathrm{M}$ & normal & all straight & $4 / 17$ short \\
\hline AD94 & 12 & $50 \mu \mathrm{M}$ & decreased & all straight & all straight \\
\hline AD95 & 10 & $50 \mu \mathrm{M}$ & normal & $6 / 10$ curved & $6 / 10$ bent \\
\hline AD115 & 15 & $10 \mu \mathrm{M}$ & decreased around swim bladder & $2 / 15$ curved & all straight \\
\hline PTU & 16 & $200 \mu \mathrm{M}$ & decreased & all straight & all straight \\
\hline
\end{tabular}

Table 4 Phenotypic description of the embryos treated at $\mathbf{2 4}$ hpf followed by automatic image acquisition.

\begin{tabular}{|c|c|c|c|c|c|}
\hline Cpd & Embryo Number & Conc. & Pigment & Tail & Trunk \\
\hline DMSO & 16 & $0.1 \%$ & normal & all straight & all straight \\
\hline DAPT & 14 & $50 \mu \mathrm{M}$ & decreased & 9/14 curved & 9/14 curved \\
\hline Gleevec & 17 & $50 \mu \mathrm{M}$ & normal & all straight & all straight \\
\hline AD28 & 11 & $100 \mu \mathrm{M}$ & normal & 1/11 slightly curved & $1 / 11$ short \\
\hline AD94 & 6 & $50 \mu \mathrm{M}$ & 3/6 lighter & all straight & all straight \\
\hline AD95 & 8 & $50 \mu \mathrm{M}$ & normal & $5 / 8$ bent & 1/8 edema \\
\hline AD115 & 9 & $10 \mu \mathrm{M}$ & decreased around swim bladder & 2/9 curved & 5/9 edema \\
\hline PTU & 11 & $200 \mu \mathrm{M}$ & Decreased & all straight & all straight \\
\hline
\end{tabular}

phenotypes acquired by In Cell Analyzer were similar to those collected by conventional microscope [40]. The majority of Gleevec-treated embryos showed no defects in morphology, even at the highest concentration of 100 $\mu \mathrm{M}$. At this concentration, a decrease of pigmentation was observed in embryos treated at $24 \mathrm{hpf}$ (Table 5). AD28 and AD94 did not cause much difference in phenotypes when two different concentrations of compounds were used. AD115 was not tested since it was lethal at doses higher than $10 \mu \mathrm{M}$.
While no effect on pigmentation of AD95 at $50 \mu \mathrm{M}$ was observed, a minor reduction in pigmentation was detected when $100 \mu \mathrm{M}$ of AD95 was used to treat embryos at $24 \mathrm{hpf}$ (Table 5). The alterations in tails and trunks were more severe at the high dose of AD95. Generally, most phenotypes observed in these embryos were specific and correlated well with the dose of DAPT, Gleevec and its fragments.

To investigate the mechanistic side effects associated with GSIs and Gleevec fragments and to explore the

Table 5 Dose-dependent phenotypic alteration in the embryos treated at $\mathbf{2 4} \mathbf{~ h p f .}$

\begin{tabular}{cccccc}
\hline Cpd & Embryo Number & Conc. & Pigment & Tail & Trunk \\
\hline DMSO & 11 & $0.1 \%$ & normal & all straight & all straight \\
\hline DAPT & 11 & $50 \mu \mathrm{M}$ & decreased & $11 / 11$ curved & $11 / 11$ curved \\
\hline DAPT & 9 & $5 \mu \mathrm{M}$ & decreased slightly & all straight & $1 / 9$ deformed \\
\hline DAPT & 4 & $0.5 \mu \mathrm{M}$ & normal & all straight & all straight \\
\hline Gleevec & 9 & $100 \mu \mathrm{M}$ & decreased & all straight & all straight \\
\hline Gleevec & 7 & $10 \mu \mathrm{M}$ & normal & 1/7 curved & $1 / 7$ short \\
\hline Gleevec & 7 & $1 \mu \mathrm{M}$ & normal & all straight & all straight \\
\hline AD28 & 14 & $100 \mu \mathrm{M}$ & decreased slightly & all straight & all straight \\
\hline AD28 & 4 & $50 \mu \mathrm{M}$ & normal & all straight & all straight \\
\hline AD94 & 8 & $100 \mu \mathrm{M}$ & lighter & all straight & all edema \\
\hline AD94 & 4 & $50 \mu \mathrm{M}$ & lighter & all curved straight & all bent, 5/7 edema \\
\hline AD95 & 7 & $100 \mu \mathrm{M}$ & lighter & all bent & all bent, 3/4 edema \\
\hline AD95 & 4 & $50 \mu \mathrm{M}$ & normal & all straight \\
\hline Untreated & 3 & & &
\end{tabular}




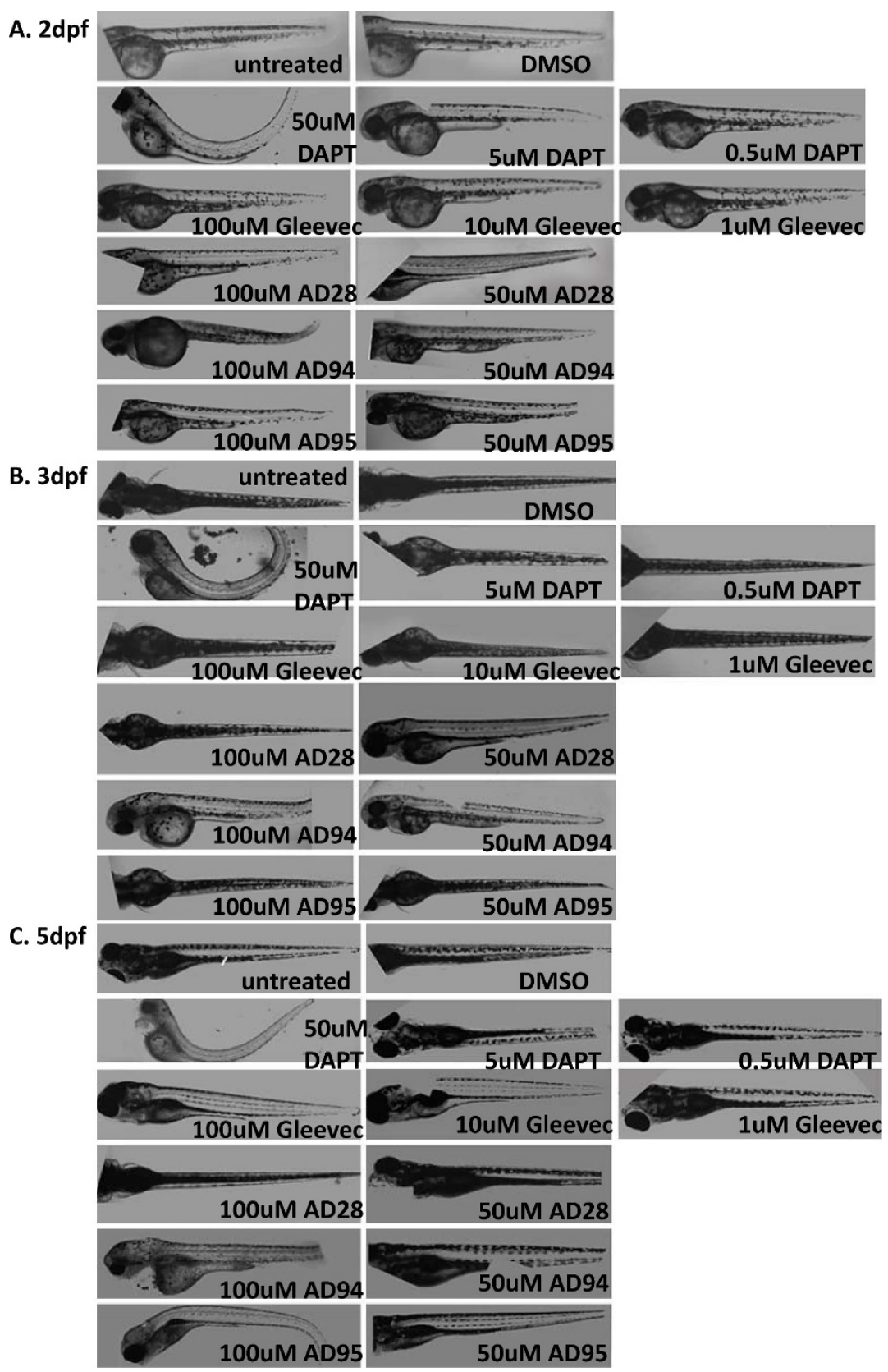

Figure 6 Automatically acquired images of embryos treated with increasing concentration of GSI or fragments of Gleevec. Images of embryos at $2 \mathrm{dpf}(\mathrm{A}), 3 \mathrm{dpf}(\mathrm{B})$, and $5 \mathrm{dpf}(\mathrm{C})$ were presented. Untreated embryos and 0.1\% DMSO-treated embryos displayed similar phenotypes. Embryos treated with $50 \mu \mathrm{M}$ DAPT showed a strong phenotype, and much less effect was observed at lower concentrations $(5 \mu \mathrm{M}$ and $0.5 \mu \mathrm{M}$ ). Gleevec was assessed at $100 \mu \mathrm{M}, 10 \mu \mathrm{M}, 1 \mu \mathrm{M}$, and embryos showed no phenotypic alteration. Embryos treated with $100 \mu \mathrm{M}$ of AD95 showed morphologic changes. These changes were not obvious when $50 \mu \mathrm{M}$ AD95 was used.

Notch signaling that may contribute to these phenotypes, the expression of the Notch downstream target gene her6 was examined by in situ hybridization and the intensity of her6 expression to the effect of inhibitors, i. e., a loss of her6 staining that corresponds to an inhibition of $\gamma$-secretase-mediated Notch signaling, were compared. This approach has been used successfully by us and others to measure $\gamma$-secretase cleavage of Notch in zebrafish [5,41].

In DMSO-treated control embryos, her6 expression was abundant in the dorsal diencephalon, retinas, ventral midbrain and ventral hindbrain (Fig. 7A). The expression of her6 was also observed in telencephalon, olfactory vesicles, branchial arches, ventral hindbrain 


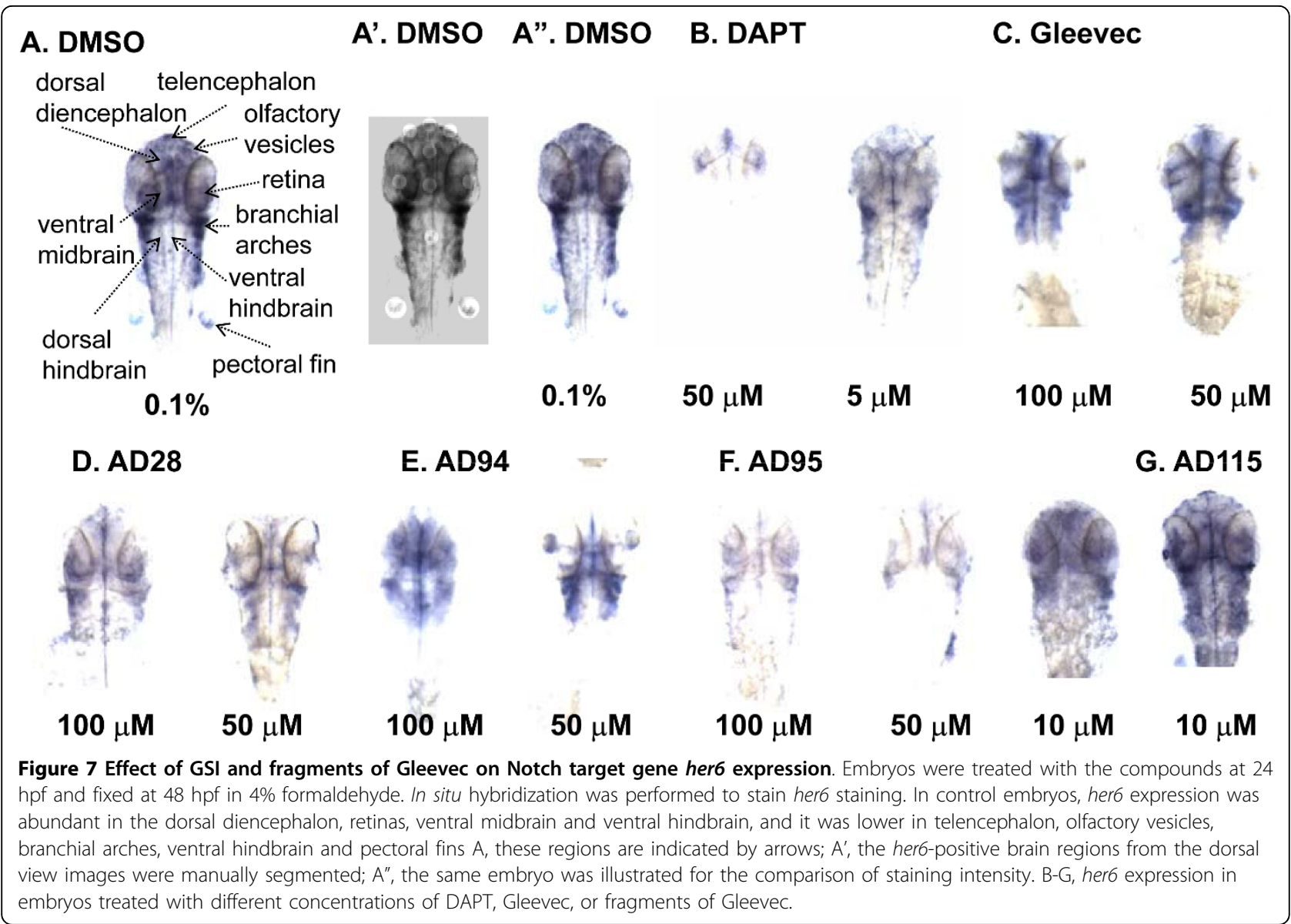

and pectoral fins (Fig. 7A). The pattern of her6 staining is consistent with previous reports [5]. In the presence of $50 \mu \mathrm{M}$ DAPT, the her6 expression was lost in most areas, demonstrating a complete inhibition of $\gamma$-secretase activity in the animal (Fig. 7B). The residual $\gamma$-secretase activity might remain in olfactory vesicles and telencephanlon where weak staining of her6 was detected (Fig. 7B). When embryos were treated with a much lower concentration of DAPT at $10 \mu \mathrm{M}$, weaker staining of her6 was observed in most areas found in DMSO-treated embryos, with almost identical staining of her6 in ventral midbrain (Fig. 7B). Treatment of embryos with Gleevec (Fig. 7C) and AD28 (Fig. 7D) caused a slight reduction of her6 staining at $100 \mu \mathrm{M}$, and the effect was much weaker when $50 \mu \mathrm{M}$ of compounds were used. The staining of her6 in embryos treated with 50 and $100 \mu \mathrm{M}$ AD94 (Fig. 7E) was similar to those treated with Gleevec and AD28. AD115 did not have any effect on her6 expression and showed identical pattern to control embryos (Fig. 7G).

AD95 treated embryos showed a regionally specific, dose-dependent inhibition of her6 expression (Fig. 7F). At $10 \mu \mathrm{M}$, AD95 did not reduce much of her6 staining, compared to DMSO-treated embryos. When embryos were treated with $50 \mu \mathrm{M}$ or $100 \mu \mathrm{M}$ of AD95, her6 staining was no longer detected in most areas, except for four regions. No difference in her6 staining in retina and branchial arches was observed between embryos treated with $50 \mu \mathrm{M}$ and $100 \mu \mathrm{M}$ AD95, but the dorsal diencephalon and ventral midbrain in embryos treated with $100 \mu \mathrm{M}$ had weaker staining than those treated with $50 \mu \mathrm{M}$ AD95. The intensity of staining in these four areas from AD95-treated embryos was reduced compared to DMSO-treated embryos.

To quantify the intensity of her6 staining, we highlighted the regions of interest (Fig 7A') that corresponded to unique brain structures (Fig. 7A). We calculated the intensity of all regions of interest and obtained the average levels of her6 expression in these embryos (Fig. 8). Overall, there was a reduction of her6 staining in all drug-treated embryos, with DAPT and AD95 showed most effects. To determine whether there was direct effect of these compounds on $\gamma$-secretase complex, we used in vitro $\gamma$-secretase activity assay to examine the Notch cleavage. Using N100 as substrate, we treated partially solubilized $\gamma$-secretase with different 


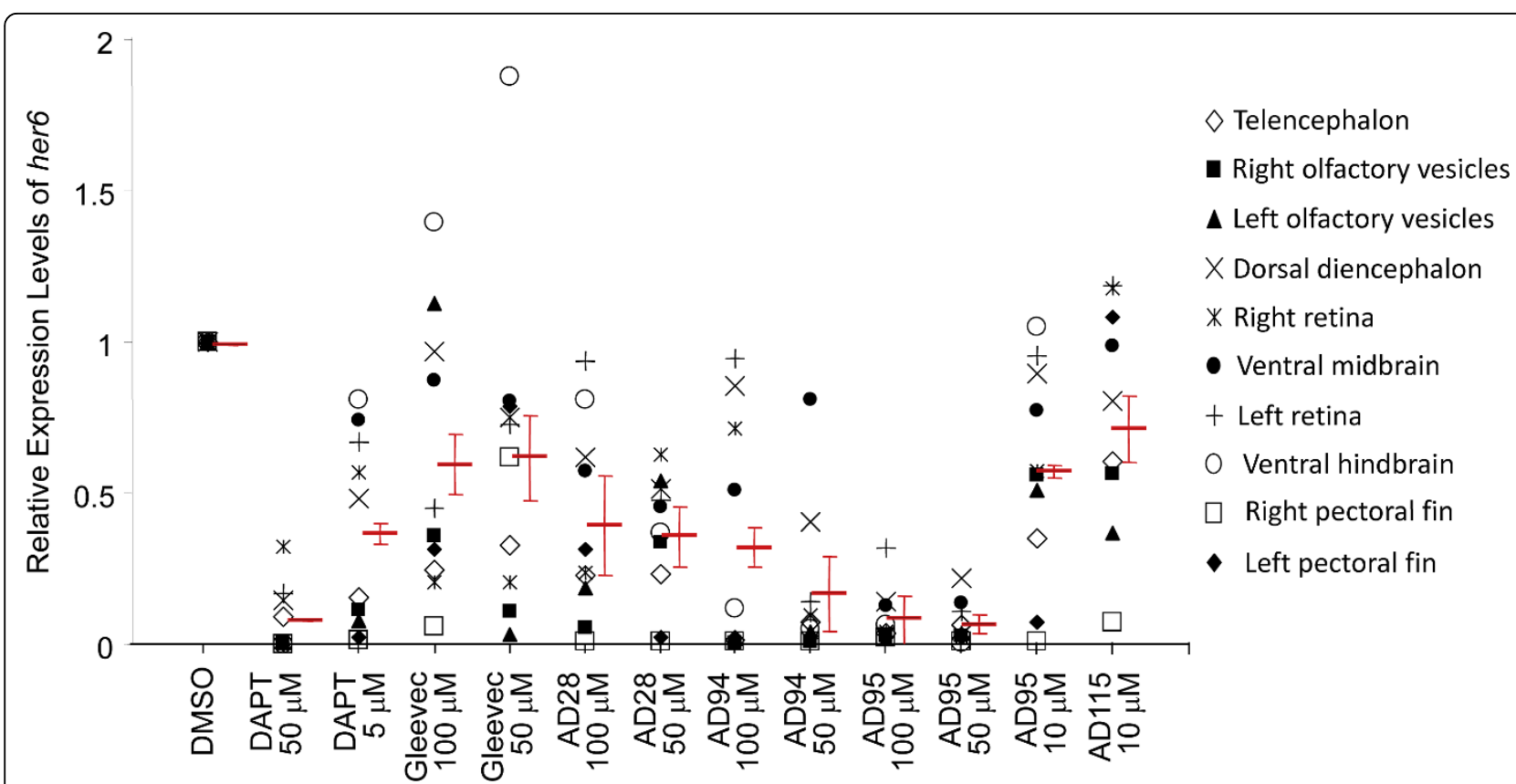

Figure 8 Quantification of Notch target gene her6 expression in embryos treated with GSI or fragments of Gleevec. Based on the segmented region of interest as highlighted in Fig. 7 A', the intensity of each ROI was quantified. The levels of her6 expression in DMSO treated embryos were normalized to 1 , and relative levels of other embryos were calculated. Different regions of embryos were quantified, and the average of staining intensity of embryos treated with an individual compound was presented by a horizontal line in red, and the bar represents the standard error of means.

compounds at $100 \mu \mathrm{M}$. While we found most compounds did not have any effect on Notch cleavage in vitro, AD 28. AD115 and DAPT showed inhibition of Notch cleavage (Table 6).

\section{Discussion}

The strength of image acquisition of living zebrafish in 96-and 384-well plates is fast data collection since no manual intervention was necessary for image recording. More importantly, the images obtained were a high quality that is comparable to those images captured by a conventional microscope. Instead of using transgenic zebrafish that express green fluorescent protein, wild type zebrafish embryos were routinely treated with

Table 6 In vitro inhibition of Notch cleavage by AD28 and AD115.

\begin{tabular}{ccc}
\hline Cpd & Conc. & In vitro Inhibition of Notch Cleavage \\
\hline DMSO & $0.10 \%$ & - \\
\hline DAPT & $100 \mu \mathrm{M}$ & + \\
\hline Gleevec & $100 \mu \mathrm{M}$ & - \\
\hline AD28 & $100 \mu \mathrm{M}$ & + \\
\hline AD94 & $100 \mu \mathrm{M}$ & - \\
\hline AD95 & $100 \mu \mathrm{M}$ & - \\
\hline AD115 & $100 \mu \mathrm{M}$ & + \\
\hline
\end{tabular}

different drugs and bright field images were acquired. For the first time, images of living zebrafish arrayed in a microtiter plate were acquired uniformly. The use of microtiter plate is an industrial standard for in vitro assays, such as enzymatic assays or cell-based metabolic assays.

Matlab and Adobe Photoshop Elements software were used for the composition and processing of automatically acquired images with minimum manual intervention. Due to the size of zebrafish embryos and the resolution that is required for phenotype analysis, the difficulties in capturing the entire embryo in 96- or 384well plates reflect a primary weakness of this approach. In this regard, housing zebrafish embryos in 384-well plates is better because less blank space is left in the images. Furthermore, compared to images of zebrafish housed in 96-well plates, a higher number of images contained a portion of zebrafish embryos living in 384well plates, which allows easier image processing by algorithms. It was noticed that parts of the zebrafish images were still missing after automatic composition as shown in several figures. This problem was approached by using more embryos and extracting essential biological information from these images that were composed and processed by Matlab and Adobe Photoshop Elements. Further development should be pursued to make this widely useful for drug screening in zebrafish. 
Zebrafish is an ideal vertebrate for primary toxicity studies in whole animals because of their cost-effectiveness, the ease of drug delivery, and their high sensitivity to toxins. Among all compounds at the tested concentrations, apoptosis was observed within a few cells. However, the effect was not massive and was comparable to the DMSO-treated embryos. In two independent experiments, AD94 showed a slightly higher apoptotic phenotype in the tail region than AD95 and DMSOtreated embryos. However, DAPT- and AD95-treated embryos showed defects in the tail and trunk development, but had fewer apoptotic cells than AD94. The occurrence of apoptosis in the tail region may not be the cause for morphological changes in the trunk since this effect was observed with all compounds tested. Therefore, perhaps compound-produced defects are more mechanistic toxicities induced by the blockage of specific pathways, e.g., an inhibition of Notch signaling rather apoptosis.

The simplification of high throughput drug screening in whole animals was illustrated in this test of zebrafish that were treated with different concentrations of various compounds. Although we had only used a few concentrations in this study, this limitation could be resolved in the future when more concentrations are tested for potential lead compounds. The number of images varied among compounds, depending on fish survival, positioning, and timing of photo acquisition. Images taken at earlier stages, such as 2 or $3 \mathrm{dpf}$, were usually more informative since embryos were immobile and both dorsal and lateral views could be obtained. At the later stages, sometimes only dorsal view can be imaged, as zebrafish mainly maintain a dorsal position. Nevertheless, we have successfully obtained high-quality images of zebrafish growing in 384 well plates, and the advance we have achieved is not only the quality of current zebrafish images but also the quantity of potential images we can acquire in a short period. The scope of developing a complete set of techniques to automatically acquire living zebrafish in a 384 well plates evolves with the advance of optical instruments and computing power. The current set of techniques allow a bench scientist to perform drug screening in a living vertebrate, and further automation could be developed, e.g., applying robotics for liquid handling. Exploration of this technique should be pursued to make it widely useful for drug screening in vertebrate animals.

In this study, phenotypes of zebrafish treated with known $\gamma$-secretase inhibitors, DAPT, Gleevec, and its fragments were examined. DAPT-treated embryos showed most defects in tail curvature, pigmentation and craniofacial structures as previously reported [42]. Over $90 \%$ of the Gleevec-treated embryos displayed a wild- type phenotype, and a few embryos showed a short, but not curved tail. One of the smaller fragments of Gleevec, AD28, has the least effect in all of the embryonic studies performed. This may be due to the simplicity of its structure such that AD28 may not have key moieties or interactions necessary for subsequent findings observed with Gleevec and AD95.

Fragment AD115 lacked A $\beta$ inhibition and caused mortality of all fish at $50 \mu \mathrm{M}$. Lowering the concentration of AD115 to $10 \mu \mathrm{M}$ also produced embryonic defects, such as pigmentation defects around the swim bladder and defects in craniofacial development. Also, even at this lower concentration, bumps around the gastrointestinal tract were observed. These results suggest that AD115 has significance differences in its structure from both Gleevec and AD95 such that treatment of zebrafish embryos with AD115 yield undesirable effects versus the overall results observed with both Gleevec and AD95. These differences in findings indicate that there are compounds within a chemical series or analogs thereof that could set the stage for identifying improved candidate compounds as potential therapeutic agents.

The results indicate that AD95 clearly reduces $A \beta$ production but also affects the morphology of zebrafish embryos as does AD94 and AD115. If compounds such as AD95 were to be pursued as potential GSIs as a possibly therapy for the treatment of $\mathrm{AD}$, Notch processing would have to be examined in much details, and AD95 and analogs need to be further explored for selectively inhibiting APP processing. Since APP and Notch are competitively processed by $\gamma$-secretase [43], it is essential to selectively inhibit the cleavage of APP substrate and not Notch. It is interesting that AD95-treated embryos showed normal V-shaped somites unlike DAPT-treated embryos. Perhaps DAPT and AD95 block $\gamma$-secretase differently and perturb unrelated downstream pathways which are partly illustrated by somitogenesis, another interesting facet of this research to further explore. While Gleevec, AD28 and AD94 showed slight reduction of her6 staining, their phenotypes were not completely identical. An animal treated with compounds usually show many phenotypes, and some of them are related to Notch signaling. We do not expect that all phenomenon found in these fish are caused by altered Notch signaling, as other metabolic pathways might be changed in the presence of these compounds. Similarly, several compounds showed different potencies in vitro and in vivo, strongly suggesting that additional components are involved in mediating the effect of GSI and fragments of Gleevec.

\section{Conclusion}

Two methods were used to acquire images of zebrafish embryos that were treated with DAPT, Gleevec, and 
fragments of Gleevec, the conventional microscope imaging and a new semi-automated image acquisition method. Easy compound delivery and good resolution of images result in the detailed examination of the effects of potential drugs on the phenotype of zebrafish. Hence, this approach provides a platform for a high-throughput screen of a library of compounds in a whole animal and establishes the zebrafish as a model vertebrate for screening therapeutic agents for $\mathrm{AD}$ and other diseases.

\section{Abbreviations}

AD: Alzheimer's disease; $A \beta$ : amyloid $\beta$ protein; Abl: Abelson leukemia; dpf: days post fertilization; GSI: $\gamma$-secretase inhibitor; hpf: hours post fertilization; NICD: Notch intracellular domain.

\section{Acknowledgements}

We would like to thank Dr. Pamela Raymond for the her6 cDNA, Dr. Peter Seubert and Dr. Dale Schenk for antibodies 2G3, 21F12 and 266, Dr. Ananda Kuppana for the synthesis of all fragments of Gleevec, Dr. Elizabeth A Heilig for helpful discussion. This study was supported by NIH grant AG015379 (WX).

\section{Author details}

${ }^{1}$ Center for Neurologic Diseases, Department of Neurology, Brigham and Women's Hospital, Harvard Medical School, Harvard University, Boston, MA, USA. 'Department of Radiology, Brigham and Women's Hospital, Harvard Medical School, Harvard University, Boston, MA, USA. ${ }^{3}$ Department of Radiology, The Methodist Hospital Research Institute, Weill Medical College of Cornell University, Houston, TX, USA.

\section{Authors' contributions}

DA and TY carried out biochemical and zebrafish experiments, XX designed algorithms for image processing, STW participated in the study design, CEA provided compounds for zebrafish treatment, WX designed the study, DA and WX wrote the manuscript. All authors read and approved the manuscript.

\section{Competing interests}

The authors declare that they have no competing interests.

Received: 25 September 2008 Accepted: 22 March 2010 Published: 22 March 2010

\section{References}

1. Moon HS, Jacobson EM, Khersonsky SM, Luzung MR, Walsh DP, Xiong WN, Lee JW, Parikh PB, Lam JC, Kang TW, et al: A novel microtubule destabilizing entity from orthogonal synthesis of triazine library and zebrafish embryo screening. Journal of the American Chemical Society 2002, 124(39):11608-11609.

2. Zhong TP, Childs S, Leu JP, Fishman MC: Gridlock signalling pathway fashions the first embryonic artery. Nature 2001, 414(6860):216-220.

3. Peterson RT, Shaw SY, Peterson TA, Milan DJ, Zhong TP, Schreiber SL, MacRae CA, Fishman MC: Chemical suppression of a genetic mutation in a zebrafish model of aortic coarctation. Nature Biotechnology 2004, 22(5):595-599.

4. Liu T, Lu J, Wang Y, Campbell WA, Huang L, Zhu J, Xia W, Wong STC: Computerized image analysis for quantitative neuronal phenotyping in zebrafish. J Neurosci Methods 2006, 153:190-202.

5. Campbell WA, Yang HW, Zetterberg H, Baulac S, Sears JA, Liu T, Wong STC, Zhong TP, Xia W: Zebrafish lacking Alzheimer Presenilin Enhancer 2 (Pen-2) demonstrate excessive p53 dependent apoptosis and neuronal loss. J Neurochem 2006, 96:1423-1440.

6. Selkoe DJ: Translating cell biology into therapeutic advances in Alzheimer's disease. Nature 1999, 399(Supp):A23-A31.

7. Xia W: Secretases as potential targets for treatment of Alzheimer's disease. Alzheimer's Disease: A Physician's Guide to Practical Management Totowa, NJ: Humana PressRichter RW, Richter BZ 2003.
8. Takasugi N, Tomita T, Hayashi I, Tsuruoka M, Niimura M, Takahashi Y, Thinakaran G, Iwatsubo T: The role of presenilin cofactors in the gammasecretase complex. Nature 2003, 422(6930):438-441.

9. Kimberly W, LaVoie M, Ostaszewski BLYW, Wolfe MS, Selkoe DJ: Gammasecretase is a membrane protein complex comprised of presenilin, nicastrin, Aph-1, and Pen-2. Proc Natl Acad Sci USA 2003, 100(11):6382-6387.

10. Francis R, McGrath G, Zhang J, Ruddy D, Sym M, Apfeld J, Nicoll M, Maxwell M, Hai B, Ellis MC, et al: aph-1 and pen-2 are required for Notch pathway signaling, g-secretase cleavage of bAPP and presenilin protein accumulation. Dev Cell 2002, 3:85-97.

11. Wolfe MS, Xia W, Ostaszewski BL, Diehl TS, Kimberly WT, Selkoe DJ: Two transmembrane aspartates in presenilin-1 required for presenilin endoproteolysis and $\gamma$-secretase activity. Nature 1999, 398:513-517.

12. Grabher $\mathrm{C}$, von Boehmer $H$, Look AT: Notch 1 activation in the molecular pathogenesis of T-cell acute lymphoblastic leukaemia. Nat Rev Cancer 2006, 6(5):347-359.

13. Xia W, Xu H: Amyloid Precursor Protein, A Practical Approach. Boca Raton, FL.: CRC Press 2004.

14. Xia W, Wolfe M: Intramembrane proteolysis by presenilin and presenilinlike proteases. J Cell Sci 2003, 116(Pt 14):2839-2844.

15. Donoviel D, Hadjantonakis A, Ikeda M, Zheng H, St George Hyslop P, Bernstein A: Mice lacking both presenilin genes exhibitearlyembryonic patterningdefects. Genes Dev 1999, 13:2801-2810.

16. Mumm JS, Schroeter EH, Saxena MT, Griesemer A, Tian X, Pan DJ, Ray WJ, Kopan R: A ligand-induced extracellular cleavage regulates gammasecretase-like proteolytic activation of Notch1. Mol Cell 2000, 5(2):197-206.

17. Artavanis-Tsakonas $S$, Rand MD, Lake RJ: Notch signaling: cell fate control and signal integration in development. Science 1999, 284(5415): $770-776$.

18. Holley SA: The genetics and embryology of zebrafish metamerism. Dev Dyn 2007, 236(6):1422-1449.

19. Holley SA, Geisler R, Nusslein-Volhard C: Control of her1 expression during zebrafish somitogenesis by a delta-dependent oscillator and an independent wave-front activity. Genes Dev 2000, 14(13):1678-1690.

20. Selkoe D, Kopan R: Notch and Presenilin: Regulated Intramembrane Proteolysis Links Development and Degeneration. Annu Rev Neurosci 2003, 26:565-97.

21. Hatakeyama J, Bessho Y, Katoh K, Ookawara S, Fujioka M, Guillemot F, Kageyama R: Hes genes regulate size, shape and histogenesis of the nervous system by control of the timing of neural stem cell differentiation. Development 2004, 131(22):5539-5550.

22. Jiang $Y$ J, Brand $M$, Heisenberg CP, Beuchle D, Furutani-Seiki M, Kelsh RN, Warga RM, Granato M, Haffter P, Hammerschmidt M, et al: Mutations affecting neurogenesis and brain morphology in the zebrafish, Danio rerio. Development 1996, 123:205-216.

23. van Eeden FJ, Granato $M$, Schach U, Brand M, Furutani-Seiki M, Haffter $P$, Hammerschmidt M, Heisenberg CP, Jiang YJ, Kane DA, et al: Mutations affecting somite formation and patterning in the zebrafish, Danio rerio. Development 1996, 123:153-164.

24. Geling A, Steiner H, Willem M, Bally-Cuif $L$, Haass C: A gamma-secretase inhibitor blocks Notch signaling in vivo and causes a severe neurogenic phenotype in zebrafish. EMBO Rep 2002, 3(7):688-694.

25. Weng AP, Ferrando AA, Lee W, Morris JPt, Silverman LB, Sanchez-lrizarry $C$, Blacklow SC, Look AT, Aster JC: Activating mutations of NOTCH1 in human T cell acute lymphoblastic leukemia. Science 2004, 306(5694):269-271.

26. Kindler T, Cornejo MG, Scholl C, Liu J, Leeman DS, Haydu JE, Frohling S, Lee BH, Gilliland DG: K-RasG12D-induced T-cell lymphoblastic lymphoma/ leukemias harbor Notch1 mutations and are sensitive to \{gamma\}secretase inhibitors. Blood 2008, 112:3373-82.

27. Yao J, Duan L, Fan M, Wu X: Gamma-secretase inhibitors exerts antitumor activity via down-regulation of Notch and Nuclear factor kappa B in human tongue carcinoma cells. Oral Dis 2007, 13(6):555-563.

28. Suwanjunee S, Wongchana W, Palaga T: Inhibition of gamma-secretase affects proliferation of leukemia and hepatoma cell lines through Notch signaling. Anticancer Drugs 2008, 19(5):477-486.

29. Mizuno T, Yamasaki N, Miyazaki K, Tazaki T, Koller R, Oda H, Honda Zl, Ochi M, Wolff $L$, Honda H: Overexpression/enhanced kinase activity of $B C R / A B L$ and altered expression of Notch1 induced acute leukemia in p210BCR/ABL transgenic mice. Oncogene 2008, 27(24):3465-3474. 
30. Nagar B, Bornmann WG, Pellicena P, Schindler T, Veach DR, Miller WT, Clarkson B, Kuriyan J: Crystal structures of the kinase domain of c-Abl in complex with the small molecule inhibitors PD173955 and imatinib (STI571). Cancer Res 2002, 62(15):4236-4243.

31. Schindler T, Bornmann W, Pellicena P, Miller WT, Clarkson B, Kuriyan J: Structural mechanism for STI-571 inhibition of abelson tyrosine kinase. Science 2000, 289(5486):1938-1942.

32. Noble ME, Endicott JA, Johnson LN: Protein kinase inhibitors: insights into drug design from structure. Science 2004, 303(5665):1800-1805.

33. Netzer WJ, Dou F, Cai D, Veach D, Jean S, Li Y, Bornmann WG, Clarkson B, $\mathrm{Xu} H$, Greengard P: Gleevec inhibits beta-amyloid production but not Notch cleavage. Proc Natl Acad Sci USA 2003, 100(21):12444-12449, Epub 12003 oct 12441.

34. Kim DH, Sun Y, Yun S, Kim B, Hwang CN, Nelson B, Lee SH: Mechanical property characterization of the zebrafish embryo chorion. Conf Proc IEEE Eng Med Biol Soc 2004, 7:5061-5064.

35. Xia W, Ray WJ, Ostaszewski BL, Rahmati T, Kimberly WT, Wolfe MS, Zhang J, Goate AM, Selkoe DJ: Presenilin complexes with the C-terminal fragments of amyloid precursor protein at the sites of amyloid beta-protein generation. Proc Natl Acad Sci USA 2000, 97(16):9299-9304.

36. Johnson-Wood K, Lee M, Motter R, Hu K, Gordon G, Barbour R, Khan K, Gordon M, Tan H, Games D, et al: Amyloid precursor protein processing and $\mathrm{A}$ beta42 deposition in a transgenic mouse model of Alzheimer disease. Proc Natl Acad Sci USA 1997, 94(4):1550-1555.

37. Thisse C, Thisse B, Schilling TF, Postlethwait JH: Structure of the zebrafish snail1 gene and its expression in wild-type, spadetail, and no tail mutant embryos. Development 1993, 119:1203-1215.

38. Otsu N: A threshold selection method from grey level histograms. IEEE Transactions on Systems, Man and Cybernetics 1978, 8:62-66.

39. Fraering PC, LaVoie MJ, Ye W, Ostaszewski BL, Kimberly WT, Selkoe DJ Wolfe MS: Detergent-dependent dissociation of active gamma-secretase reveals an interaction between Pen-2 and PS1-NTF and offers a model for subunit organization within the complex. Biochemistry 2004, 43(2):323-333.

40. Yang T, Arslanova D, Gu Y, Augelli-Szafran C, Xia W: Quantification of gamma-secretase modulation differentiates inhibitor compound selectivity between two substrates Notch and amyloid precursor protein. Mol Brain 2008, 1(1):15.

41. Bernardos RL, Lentz SI, Wolfe MS, Raymond PA: Notch-Delta signaling is required for spatial patterning and Muller glia differentiation in the zebrafish retina. Dev Biol 2005, 278(2):381-395.

42. Geling A, Steiner H, Willem M, Bally-Cuif L, Haass C: A gamma-secretase inhibitor blocks Notch signaling in vivo and causes a severe neurogenic phenotype in zebrafish. EMBO Rep 2002, 3(7):688-694.

43. Berezovska O, Jack C, Deng A, Gastineau N, Rebeck GW, Hyman BT: Notch1 and amyloid precursor protein are competitive substrates for presenilin1-dependent gamma-secretase cleavage. J Biol Chem 2001, 276(32):30018-30023.

doi:10.1186/1472-6750-10-24

Cite this article as: Arslanova et al:: Phenotypic analysis of images of zebrafish treated with Alzheimer's $\gamma$-secretase inhibitors. BMC

Biotechnology 2010 10:24

\section{Submit your next manuscript to BioMed Central and take full advantage of:}

- Convenient online submission

- Thorough peer review

- No space constraints or color figure charges

- Immediate publication on acceptance

- Inclusion in PubMed, CAS, Scopus and Google Scholar

- Research which is freely available for redistribution

Submit your manuscript at www.biomedcentral.com/submit
Biomed Central 